\title{
Unusual Presentation of Complete Duodenal Rupture in a 3-Year-Old Child
}

\author{
Amulya K. Saxena $^{\text {a }}$ Cornelia van Tuil $^{\text {b }}$

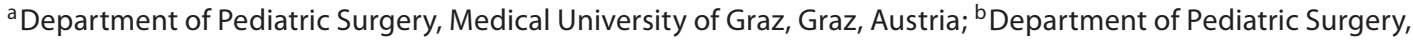 \\ Westfälische Wilhelms University, Münster, Germany
}

The case of a 3-year-old girl with acute abdomen after 'mild abdominal trauma' is reported. The child was pushed by a car reversing on slow speed in the driveway. The parents recollected that the incident was not remarkable. It was only $18 \mathrm{~h}$ after the incident that the child complained of abdominal pain and was presented to our emergency department. Clinical examination revealed a somnolent child without injury marks or abdominal distention. An emergency ultrasound demonstrated small pockets of fluids scattered in the abdomen and complete absence of bowel movements.

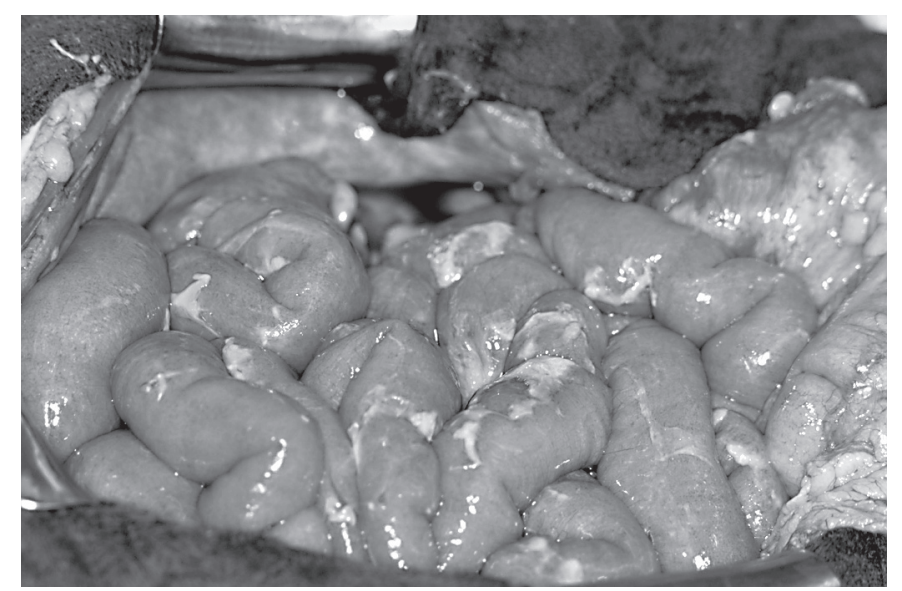

Fig. 1. View of the bowel on explorative laparotomy showing fibrinous plaques distributed along the entire length.

\section{KARGER}

Fax +41613061234 E-Mail karger@karger.ch www.karger.com
(C) 2007 S. Karger AG, Basel

0253-4886/07/0245-0323\$23.50/0

Accessible online at:

www.karger.com/dsu
The decision to perform an emergency laparotomy was taken. As the abdomen was explored, inflammation along with fibrin covering along the entire length of the bowel was found (fig. 1). Bile was found in the pockets of fluid between the intestinal loops. There were no signs of injury to the liver or the gall bladder. The entire bowel was examined for signs of injury or perforation. A complete rupture of the duodenum just proximal to the vertebral column was located, without any signs of injury to the neighboring parenchymatous organs (fig. 2). The ruptured duodenum was anastomosed using 4-0 vicryl. The postoperative course was uneventful.

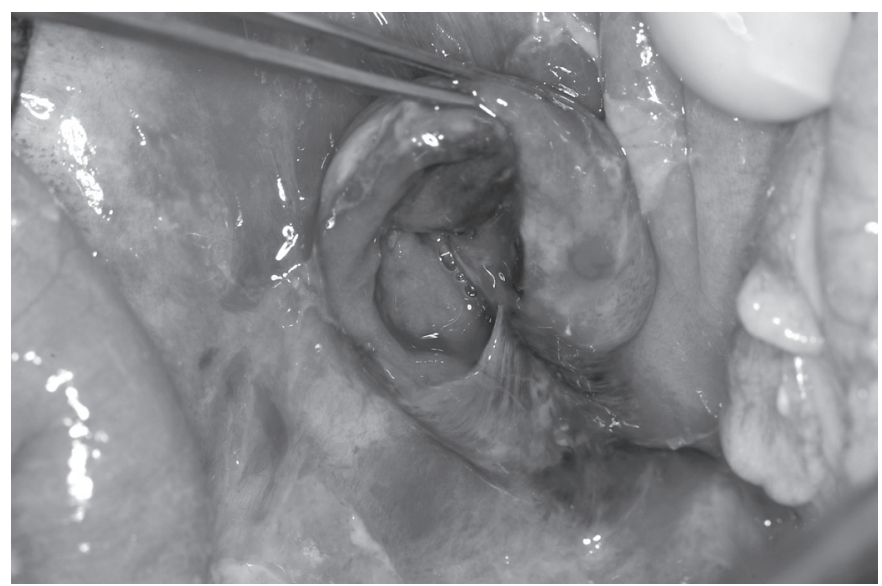

Fig. 2. View of the proximal end of the ruptured duodenum around the ligament of Trietz without injury to the neighboring organs.

Amulya K. Saxena, MD

Department of Pediatric Surgery, Medical University of Graz

Auenbruggerplatz 34

AT-8036 Graz (Austria)

Tel. +43 316385 3762, Fax +43 316385 3775, E-Mail amulya.saxena@meduni-graz.at 